\title{
The Role of Temperature on the Development of Circadian Rhythms in Honey Bee Workers
}

\section{Authors:}

Manuel A. Giannoni-Guzmán ${ }^{1}$, Janpierre Aleman-Rios², Alexander M. Melendez Moreno², Gabriel Diaz Hernandez ${ }^{2}$, Melina Perez ${ }^{2}$, Darimar Loubriel ${ }^{2}$, Tugrul Giray ${ }^{2}$ and Jose L. Agosto-Rivera ${ }^{2}$

\section{Affiliations:}

1. Department of Biological Sciences, Vanderbilt University, Nashville, TN, USA

2. Department of Biology, University of Puerto Rico Rio Piedras Campus, San Juan, PR

Corresponding author: Manuel A. Giannoni-Guzmán

e-mail: manuel.giannoni10@gmail.com

Key words: Honey bee, development, circadian, workers, temperature 


\section{Abstract:}

Circadian rhythms in honey bees are involved in various processes that impact colony

3 survival. For example, young nurses take care of the brood constantly throughout the day and

4 lack circadian rhythms, while foragers use the circadian clock to remember and predict food

5 availability in subsequent days. Previous studies suggested that development of circadian

6 rhythms both in the field and the laboratory began around 7-9 days of age. However, not much

7 is understood about the postembryonic development of circadian rhythms in honey bees. In

8 the current study, we examine the effects of socially regulated colony temperature on the

9 ontogeny of circadian rhythms of young workers under controlled laboratory conditions. We

10 hypothesized that temperature plays a key role in the development of circadian rhythmicity in

11 young workers. Our results show that young workers kept at $35^{\circ} \mathrm{C}$ develop circadian

12 rhythmicity faster and in greater proportion than bees kept at $25^{\circ} \mathrm{C}$. In addition, we examine if

13 the effect of colony temperature during the first 48 hours after emergence is enough to

14 observe effects on the rate and proportion of development of circadian rhythmicity. We

15 observed that twice as many individuals that were exposed to $35^{\circ} \mathrm{C}$ during the first 48 hours

16 develop circadian rhythms compared to individuals kept at $25^{\circ} \mathrm{C}$. In addition, we observed

17 differences in the average endogenous period length consistent with temperature

18 compensation of the circadian rhythms between the $25^{\circ} \mathrm{C}$ and $35^{\circ} \mathrm{C}$ cohorts. We also observed

19 differences in the degree of period length variation between the $25^{\circ} \mathrm{C}$ and $35^{\circ} \mathrm{C}$ cohorts, which

20 combined with the proportion of arrhythmic individuals and survival data suggest that

21 development of circadian rhythms is incomplete in individuals exposed to $25^{\circ} \mathrm{C}$ adult

22 emergence. This study shows that temperature, which is socially regulated inside the hive, is

23 a key factor that influences the ontogeny of circadian rhythmicity of workers. 


\section{Introduction:}

The circadian clock of honey bees is important in complex physiological processes,

28 such as spatiotemporal learning, time perception and sun-compass navigation (Goodwin and

29 Lewis, 1987; Moore et al., 1998; Van Nest and Moore, 2012; von Frisch, 1967; Wagner et al.,

30 2013). However, when it comes to development of circadian rhythms in honey bee workers,

31 scientists are just beginning to scratch the surface of what is thought to be a highly complex

32 mechanism of regulation, with components at the environmental, social, hormonal and genetic

33 levels (Eban-Rothschild et al., 2012; Moore, 2001; Moore et al., 1998; Shemesh et al., 2007).

34 In this manuscript, we study the role of environmental temperature on the ontogeny of

35 circadian rhythms of young honey bee workers.

The development of honey bee circadian rhythms is of particular interest because

37 similar to human infants, young honey bees present postembryonic development of circadian

38 rhythms before they forage (Eban-Rothschild et al., 2012; Moore et al., 1998). Furthermore,

39 in the colony, it is thought that workers will remain arrhythmic performing in-hive tasks and will

40 develop circadian rhythmicity just prior to the onset of foraging behavior, suggesting that

41 ontogeny of circadian rhythms is intertwined with age-related division of labor in the colony.

42 Studies examining the timing of in-hive tasks such as brood care found that individual 'nurses'

43 performed this task around the clock, which is thought to benefit the developing brood (Moore

44 et al., 1998).

45 In isolation, during the first days of their adult life young bees lack behavioral, 46 metabolic or daily oscillations in circadian gene expression in the brain, that are associated

47 with circadian rhythmicity. Under these constant conditions (DD, $\sim 60 \% \mathrm{RH}, 26-30^{\circ} \mathrm{C}$ ),

48 researchers have reported that ontogeny of circadian rhythmicity occurs at around 7-10 days

49 of age in $50 \%$ of the sampled subjects (Moore, 2001; Toma et al., 2000). Furthermore, under

50 these experimental conditions by 16 days of age around $25 \%$ of the bees were still arrhythmic. 
51 Since ontogeny of circadian rhythms is thought to be regulated by age-related division of labor,

52 researchers have manipulated neuroendocrine signals known to accelerate onset of foraging

53 (such as juvenile hormone, octopamine and cGMP dependent protein kinase), hypothesizing

54 a similar effect on circadian rhythms without success in individually isolated bees (Ben-

55 Shahar, 2003; Bloch et al., 2002; Meshi and Bloch, 2007). A recent study examined whether

56 the colony environment or other social cues may elicit strong circadian rhythms in young

57 workers (Eban-Rothschild et al., 2012). Their findings reveal that experiencing the colony

58 environment, either in a mesh cage or interacting with other bees for 48 hours after adult

59 emergence, resulted in strong circadian rhythms when bees were brought to the laboratory.

60 The authors of this work postulate that social cues, the colony microenvironment or a

61 combination of both plays a role in the ontogeny of circadian rhythms of young workers. Taken

62 together, these studies suggest the existence of a cue, which can be social or environmental,

63 that elicits the development of circadian rhythmicity.

Honey bee colonies are able to efficiently regulate the colony microenvironment

65 (Jones et al., 2004, 2007; Kronenberg and Heller, 1982; Seeley, 1974; Simpson, 1961).

66 Studies have shown that bees regulate $\mathrm{CO}_{2}$ levels, humidity and temperature inside the

67 colony (Ohashi et al., 2008). In response to an increase in $\mathrm{CO}_{2}$ levels inside the colony honey

68 bee workers begin fanning until $\mathrm{CO}_{2}$ levels diminish (Seeley, 1974). While the ability of honey

69 bees to control temperature has been the main interest of researchers, humidity inside the

70 nest is also regulated by workers (Human et al., 2006). Studies have shown that colonies with

71 a naturally mated queen, are able to regulate temperature better than colonies that originate

72 from a single drone artificially inseminated queen (Jones et al., 2004). This temperature

73 control is especially important, since deviations of more that $1.5^{\circ} \mathrm{C}$ from $35^{\circ} \mathrm{C}$ at the core of

74 the hive during larval and pupal development can have lasting changes in the adult honey bee

75 (Winston, 1987). 
77 examining the endogenous rhythms of the Japanese honey bee Apis cerana show that

78 environmental temperature has a direct effect on the endogenous period length of foragers

79 (Fuchikawa and Shimizu, 2007). Recent work in our laboratory using the gentle Africanized

80 honey bee $(g A H B)$ also shows that environmental temperature affects the endogenous period

81 length in honey bee foragers (Giannoni-Guzmán et al., 2014). However, the effect of

82 temperature in the development of circadian rhythms in honey bee workers has yet to be

83 explored.

84 In the current study we examined the effects of environmental temperature on the

85 development of circadian rhythms in young workers. We hypothesized that temperature at the

86 center of the colony is important for the development of circadian rhythms in young honey bee

87 workers. In order to test this hypothesis, we isolated 1-day-old workers in locomotor activity

88 monitors either at $25^{\circ} \mathrm{C}$ or $35^{\circ} \mathrm{C}$. We examined the endogenous period length of rhythmic

89 individuals in each group, the variation in period length and the mortality between the groups.

90 Lastly, given the previous body of work that indicates that the first 48 hours after emergence

91 are important for the development of circadian rhythms, we examined the effect of colony

92 temperature during these 48 hours by placing individuals at $35^{\circ} \mathrm{C}$ and then changing the

93 temperature to $25^{\circ} \mathrm{C}$. Our results highlight the importance of socially regulated temperature of

94 the hive in the ontogeny of circadian rhythms in honey bee workers. 
Materials and Methods:

\section{Honey bees Colonies and collections:}

Colonies used in our experiments had mated queens that were laying eggs of gentle

103 Africanized honey bees (Gallindo-Cardona et al., 2013). These colonies were located at the

104 University of Puerto Rico (UPR) Gurabo Experimental Station in Gurabo, Puerto Rico. For all 105 experiments, brood frames were collected, workers were removed and then the frame was

106 stored in an incubator overnight $\left(\sim 35^{\circ} \mathrm{C}\right)$. The following morning, bees that emerged from the

107 frames were collected and placed inside individual tubes for locomotor activity monitoring.

108 The first colony of experiment 1 was examined on November 29, 2012 (colony 1), while the

109 second colony was assayed beginning January 12, 2013 (colony 2). A total of 320 bees were

110 used in this experiment, 256 for colony 1 and 64 for colony 2. Experiment 2 examined the

111 effect of temperature during the first 48 hours after eclosion on the development of circadian

112 rhythms, fixed began on February 26, 2016.

\section{Experiment 1: Development of Circadian rhythms at $25^{\circ} \mathrm{C}$ vs. $35^{\circ} \mathrm{C}$}

115 (Percival, I-30BLL) set up under constant darkness, relative humidity of $80 \% \pm 5 \%$ and

116 temperature of $25 \pm 0.5^{\circ} \mathrm{C}$ or $35 \pm 0.5^{\circ} \mathrm{C}$ and maintained constant throughout the experiments.

117 Locomotor activity was recorded using monitors and software from Trikinetics (Waltham, MA, 118 USA) as previously described (Giannoni-Guzmán et al., 2014). Briefly, 1-day-old workers

119 were collected from the brood frame and placed inside individual tubes within the activity 120 monitoring system. Food in the form of honey candy (mixed sugar and honey) and water were

121 provided "ad-libitum" and changed as needed. Circadian rhythmicity was determined using 4

122 consecutive days of data (days 6-10), using autocorrelation analysis for 1-minute bins (Levine 123 et al., 2002). All bees were approximately the same age for periods where rhythmicity was 124 analyzed. 


\section{Experiment 2: Development of circadian rhythms after 48 hours at $35^{\circ} \mathrm{C}$}

As in experiment 1 , we carried out locomotor activity measurements using two

128 environmental chambers. In one of these the temperature during the first 48 hours was set at

$12935^{\circ} \mathrm{C}$ and afterwards lowered to $25^{\circ} \mathrm{C}$ for the remainder of the experiment. The other incubator

130 was kept at $25^{\circ} \mathrm{C}$ throughout the experiment. Food and water where provided ad libitum and

131 changed as needed.

Data analysis:

All data sets were tested for normality via a Goodness of Fit test and appropriate

134 nonparametric statistics were used were needed. The locomotor activity of each individual 135 was processed using freely available MatLab® toolboxes developed in Jeffrey Hall's

136 laboratory (Levine et al., 2002). Visual examination of locomotor activity for each individual in

137 the form of actograms was utilized to determine the age at onset of circadian rhythms.

138 Repeated measures MANOVA were utilized to determine if there were significant differences

139 between the onset of rhythmicity between each of the experimental groups. Autocorrelation

140 plots were utilized to confirm rhythmicity and calculate period length for each bee. Period

141 length analysis was calculated for days. To examine differences in average period length

142 between cohorts a two-way ANOVA was performed. To determine differences in the degree

143 of period length variation the Levine's test for equality of variance was performed.

144 To determine if environment temperature influences survival in our experiments, we

145 performed survival analysis via the Gehan-Breslow-Wilcoxon test. Furthermore, Proportional

146 Hazards analysis was performed to determine if differences in mortality were the result of

147 independent factors or a combination of different factors. All statistical analyses were

148 performed using the JMP ${ }^{T M}$ software package from SAS (SAS Institute Inc., 2009); graphs 


\section{Results:}

\section{A) Colony 1}

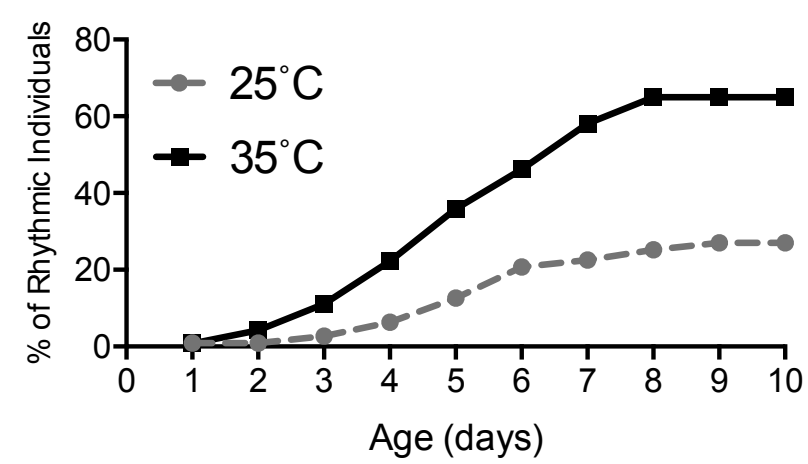

\section{B) Colony 2}

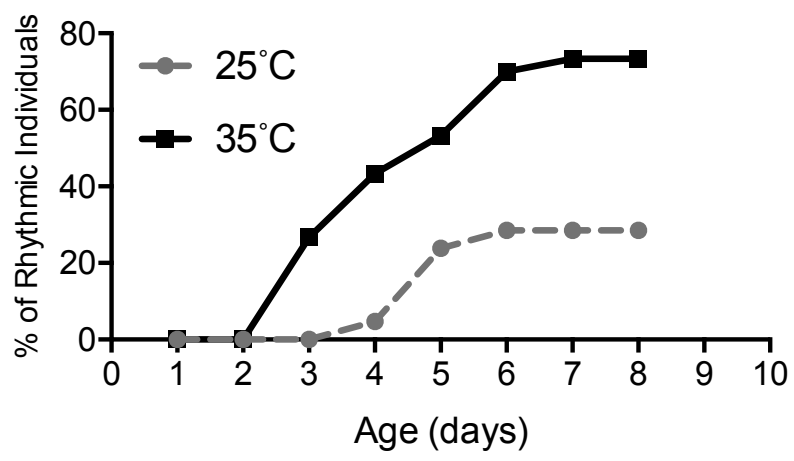

Figure 1. Rate and proportion of young workers developing circadian rhythms is greater at $35^{\circ} \mathrm{C}$ than at $25^{\circ} \mathrm{C}$. Cumulative distribution of rhythmic young workers at $25^{\circ} \mathrm{C}$ and $35^{\circ} \mathrm{C}$ in constant darkness for two colonies. At $35^{\circ} \mathrm{C}$ the rate of development and the proportion of 1-day-old bees developing strong circadian rhythms were higher than at $25^{\circ} \mathrm{C}$. Repeated measures MANOVA for each of the colonies samples yielded significant differences between the $25^{\circ} \mathrm{C}$ and $35^{\circ} \mathrm{C}$ conditions for both colonies sampled A) Colony $1 \quad(F=3.94, \quad d f=9$, $\mathrm{p}<<0.001)$. B) Colony $2 \quad(F=3.29, d f=7$, $p<0.01)$. Consistent with the hypothesis that brood nest temperature is important for the 171 ontogeny of circadian rhythms, our results show that young workers kept at $35^{\circ} \mathrm{C}$ developed 172 circadian rhythms as early as 2 days of age compared to young workers kept at $25^{\circ} \mathrm{C}$, which 173 began developing rhythms between $4-5$ days of age (Figure 1 ). In addition, at $35^{\circ} \mathrm{C}$ between $17460-80 \%$ of workers developed circadian rhythms, while at $25^{\circ} \mathrm{C}$ less than $30 \%$ of the bees 175 developed rhythmicity (Repeated measures MANOVA, colony 1: $F=3.94$, df=9, $p<<0.001$; 176 colony 2: $F=3.29, d f=7, p<0.01$ ) (Figure 1 ). This result indicates that colony temperature plays 177 a key role in the development of circadian rhythmicity. Further examination of locomotor 
178 activity plots of individuals that developed circadian rhythms revealed not only that the onset

179 of circadian rhythmicity was different between groups, also that the endogenous period length

180 in young workers was different between each experimental group (Figure 2).

A) $25^{\circ} \mathrm{C}$

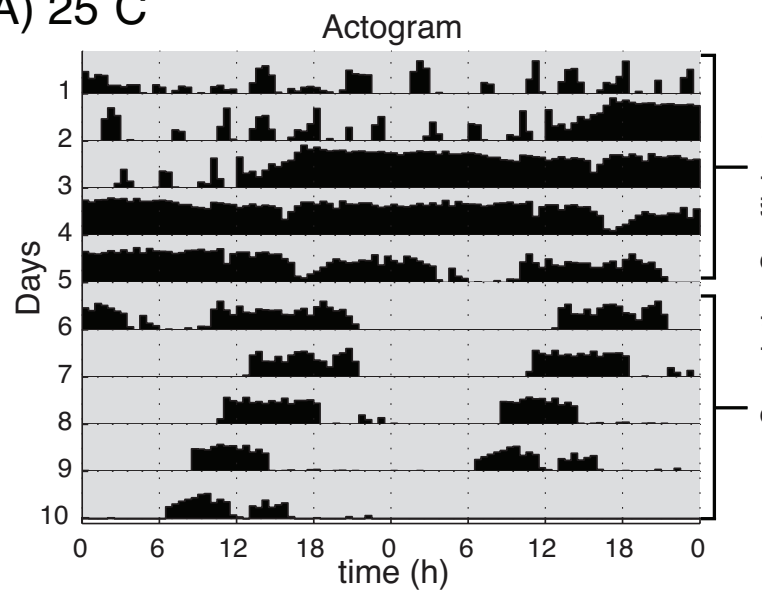

B) $35^{\circ} \mathrm{C}$

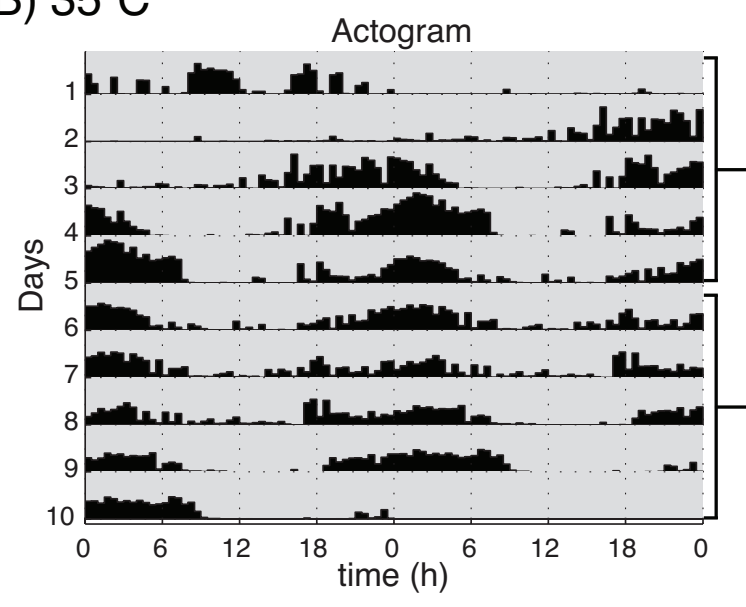

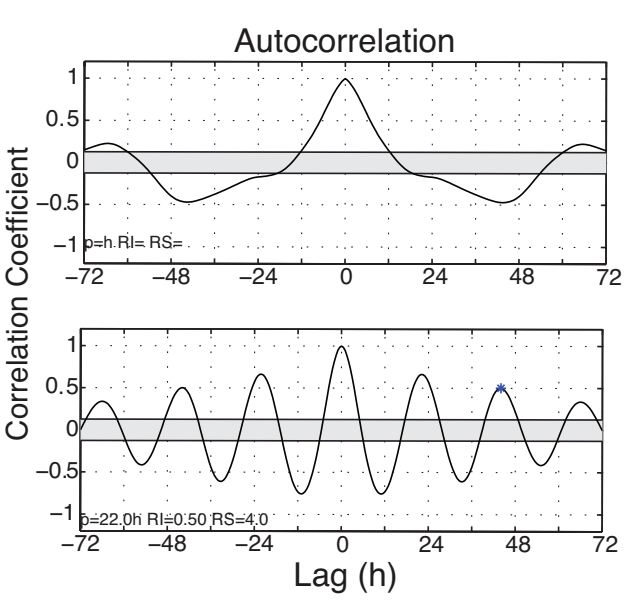

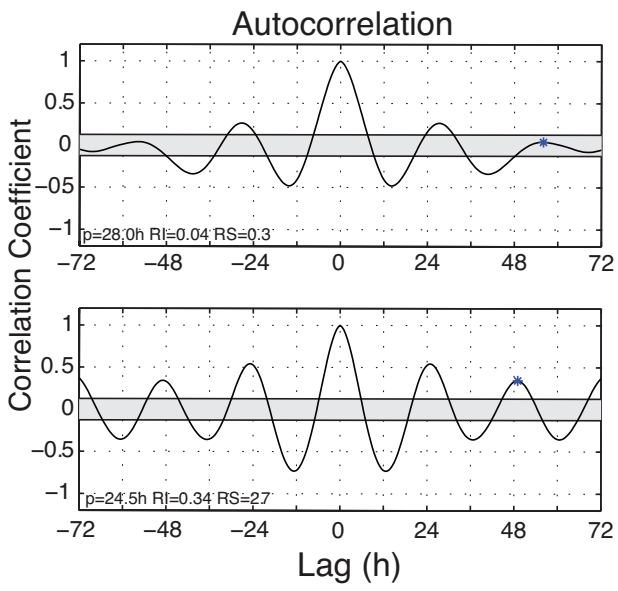

Figure 2. Locomotor activity patterns of young honey bee workers under $25^{\circ} \mathrm{C}$ or $35^{\circ} \mathrm{C}$ constant darkness. Double-plotted actograms of representative 1-day-old workers at A) $25^{\circ} \mathrm{C}$ and B) $35^{\circ} \mathrm{C}$ constant darkness. Autocorrelation plots were used to determine rhythmicity of locomotor activity and calculate the endogenous period length $(p)$, rhythm index (RI) and rhythm strength (RS), from days 15 and 6-10 for each individual. 
Recent work on different species of honey bees has shown that environmental

190 temperature affects endogenous period length of foragers (Fuchikawa and Isamu Shimizu,

191 2007; Giannoni-Guzmán et al., 2014). We hypothesized that rhythmic young workers would

192 present endogenous rhythms closer to 24 hours when assayed at $35^{\circ} \mathrm{C}$ than those assayed

193 at $25^{\circ} \mathrm{C}$. To test our hypothesis, we compared the endogenous periods of days $6-10$ for

194 rhythmic bees kept at $25^{\circ} \mathrm{C}$ or $35^{\circ} \mathrm{C}$. The resulting analysis revealed that bees kept at $25^{\circ} \mathrm{C}$

195 have an average endogenous period length of $23.10 \mathrm{hr}$, compared to that of bees kept at $35^{\circ} \mathrm{C}$,

196 whose average period was $24.5 \mathrm{hr}$ (Figure 3). This finding is consistent with previous work

197 testing the endogenous period length in foragers (Giannoni-Guzmán et al., 2014; Moore and

198 Rankin, 1985; Spangler, 1972; Toma et al., 2000).

A) Locomotor Activity Average at $25^{\circ} \mathrm{C}$
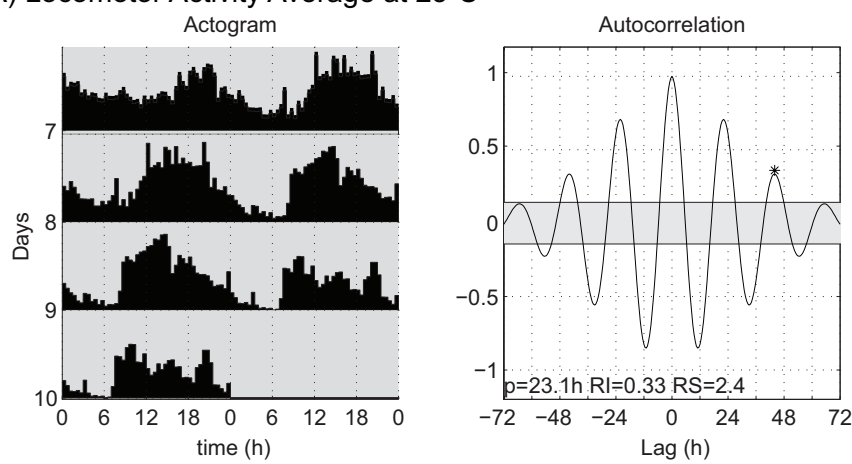

B) Locmotor Activity Average at $35^{\circ} \mathrm{C}$ Actogram
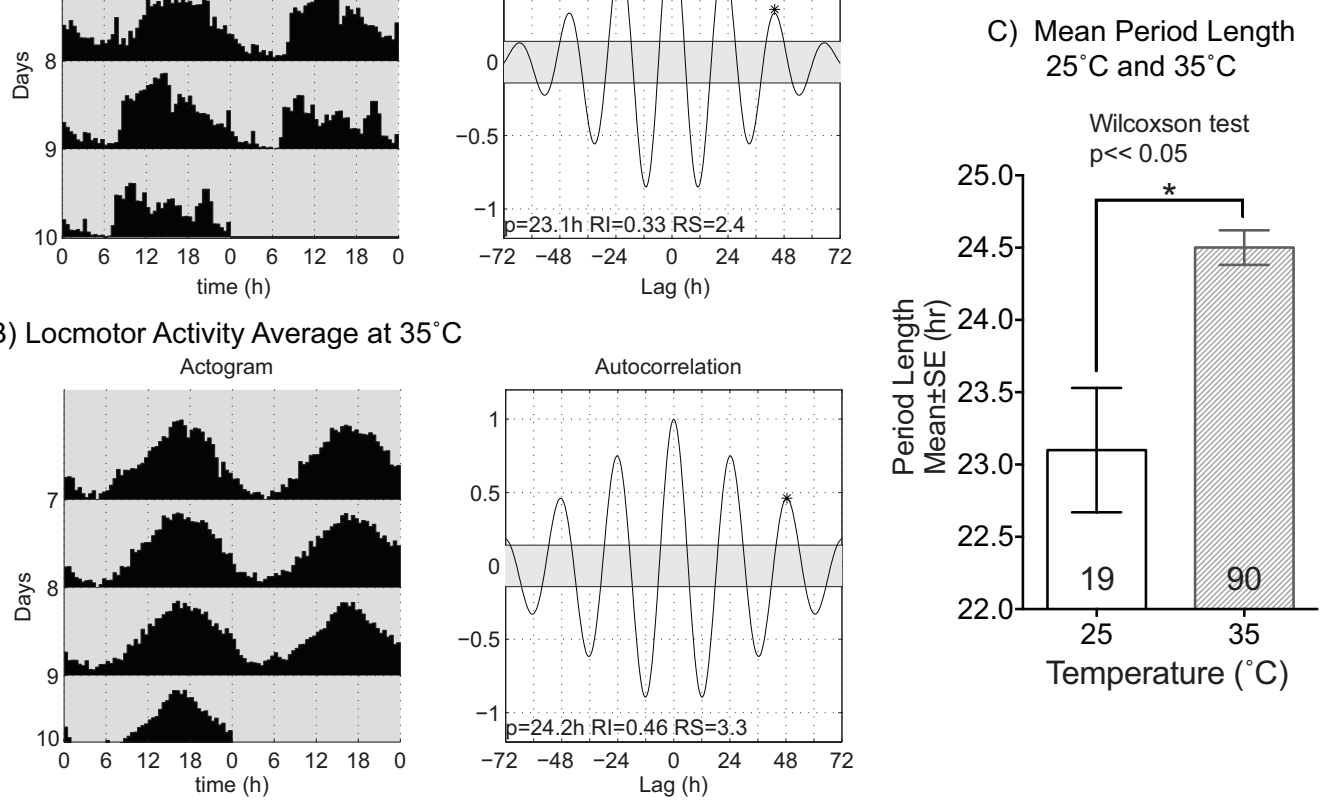

Figure 3. Average endogenous period length of young bees at $35^{\circ} \mathrm{C}$ is closer to 24 hours. Doubleplotted actograms and autocorrelations of the average locomotor profile rhythmic bees at A) $25^{\circ} \mathrm{C}$ and B) $35^{\circ} \mathrm{C}$ for days $6-10$. C) The mean period length at $35^{\circ} \mathrm{C}(24.5 \pm 0.13 \mathrm{~h}$ SEM) was closer to 24 hours and significantly different from that measured in the $25^{\circ} \mathrm{C}$ cohort $(23.10 \pm 0.29 \mathrm{~h} \mathrm{SEM}$ ) (ANOVA F=18.59, $d f=1, p<<0.01)$. 
207 higher than that of the $35^{\circ} \mathrm{C}$ group. By observing the distributions of period length for each of

208 the group it was evident that the $25^{\circ} \mathrm{C}$ group presented a larger degree of variation than the

$20935^{\circ} \mathrm{C}$ group (Figure 4A, B). To quantify this variation, we performed Levene's test of equality

210 of variance, which confirmed that period length in the $25^{\circ} \mathrm{C}$ cohort varies significantly more

211 than that of the $35^{\circ} \mathrm{C}$ cohort $(F=17.9, \mathrm{df}=1, \mathrm{p}<<0.01)$ (Figure 4C). Interestingly, this result does

212 not translate to foragers, where the degree of variation in endogenous period length was not

213 significantly different between foragers at $25^{\circ} \mathrm{C}$ or $35^{\circ} \mathrm{C}$ conditions (Levene's test, $\mathrm{F}=0.35$

$214 d f=1, p=0.56)($ Figure $4 \mathrm{C})$. Multiple comparisons between young workers and foragers at $25^{\circ} \mathrm{C}$

215 and $35^{\circ} \mathrm{C}$, revealed that the degree of variation of foragers was similar to that of young workers

216 at $35^{\circ} \mathrm{C}$ and significantly different from that of young bees at $25^{\circ} \mathrm{C}$ (Figure $4 \mathrm{C}$ ). These results

217 suggest that colony temperature after adult emergence plays an important role in the 218 development of circadian circuitry in the honey bee system.

A) Period Length Distribiution $25^{\circ} \mathrm{C}$
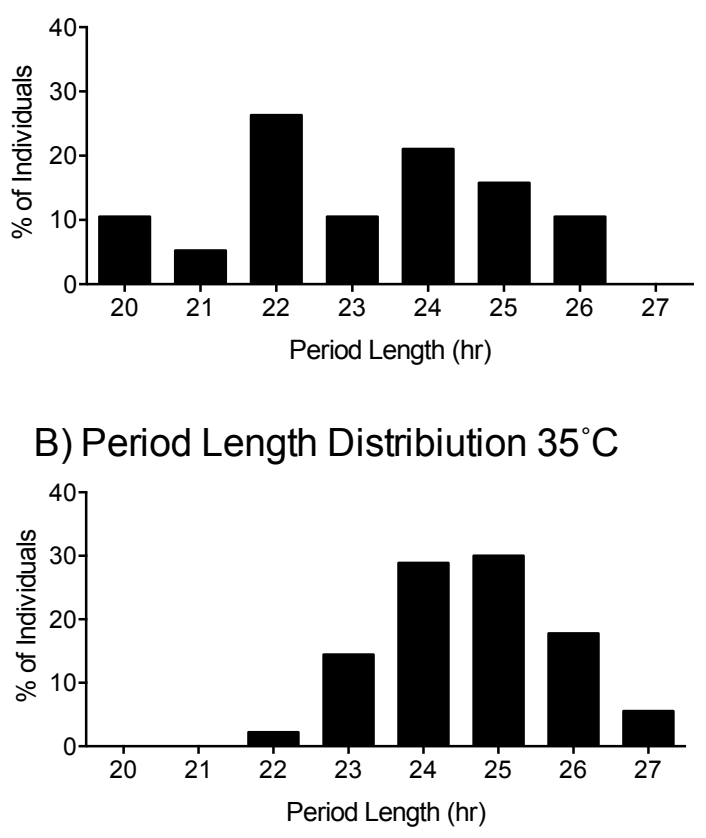

C) Degree of variation

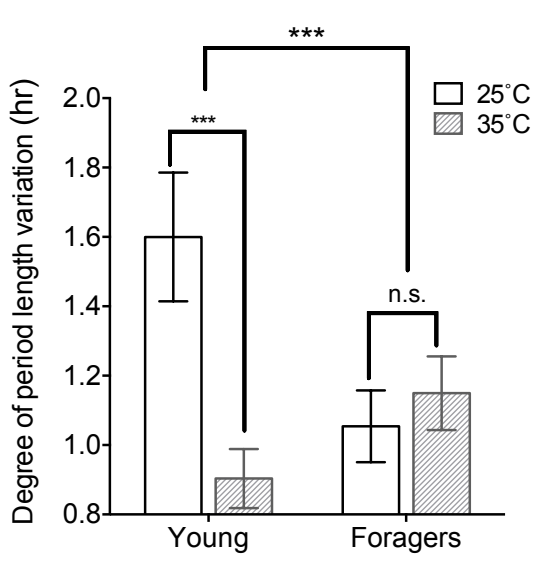


219 Figure 4. Individual variation of endogenous period length is greater at $25^{\circ} \mathrm{C}$ than at $35^{\circ} \mathrm{C}$

220 Frequency distributions of endogenous period length of days 6-10 from rhythmic young workers at $\mathbf{A}$ )

$22125^{\circ} \mathrm{C}$ and $\left.\mathrm{B}\right) 35^{\circ} \mathrm{C}$. C) Bar graph comparing the degree of period length variation as calculated by

222 Levene's test of equality of variance for young workers and foragers at $25^{\circ} \mathrm{C}$ (white bars) and $35^{\circ} \mathrm{C}$

223 (gray shaded bars). Significant differences were observed between the young worker cohorts ( $F=17.9$,

$224 \mathrm{df}=1, \mathrm{p}<<0.01)$, while differences comparison within foragers was not significant $(F=0.35 \mathrm{df}=1, p=0.56)$.

225 Multiple comparisons test revealed significant differences $(p<0.05)$ between young workers at $25^{\circ} \mathrm{C}$ and

226 foragers at either $25^{\circ} \mathrm{C}$ or $35^{\circ} \mathrm{C}$.

227 During the data analysis of the experiments, another difference that was noticed

228 between the $25^{\circ} \mathrm{C}$ and $35^{\circ} \mathrm{C}$ cohorts was their mortality. When we compared the mortality of

229 each group we observed that by day 10 only $~ 30 \%$ of bees in the $25^{\circ} \mathrm{C}$ cohort survived (Figure

$2305 \mathrm{~A})$. Significantly, this was less than half of the mortality observed in the $35^{\circ} \mathrm{C}$ cohort, where

231 more than $\sim 65 \%$ of the bees were still alive (Gehan-Breslow-Wilcoxon test, $p<<0.01$ ). This

232 result is somewhat surprising since our experiments with foragers under the same

233 experimental setup did not reveal significant differences in mortality (unpublished results).

234 Furthermore, by separating each cohort by individuals who developed or did not develop

235 circadian rhythms, we observed a relationship between arrhythmicity and mortality in both

236 groups (Figure 5B). Nonparametric Kruskal-Wallis rank sums test revealed significant

237 differences between arrhythmic and rhythmic individuals at $25^{\circ}$ and at $35^{\circ} \mathrm{C}(\mathrm{F}=78.13$, df $=3$,

$238 \mathrm{p}<<0.01$ ). Post hoc analysis using Wilcoxon each pair test uncovered significant differences

239 between 3 of the 4 groups tested, the exception being the comparison of rhythmic individuals

240 at $25^{\circ} \mathrm{C}$ and arrhythmic individuals at $35^{\circ} \mathrm{C}$. In order to ascertain potential factors playing a

241 role in the mortality of honey bee workers, we used a proportional hazards model analysis. 
245
B) Mean Survival of Rhythmic and Arrhythmic bees at $25^{\circ} \mathrm{C}$ and $35^{\circ} \mathrm{C}$

\section{A) Survival at $25^{\circ} \mathrm{C}$ and $35^{\circ} \mathrm{C}$}

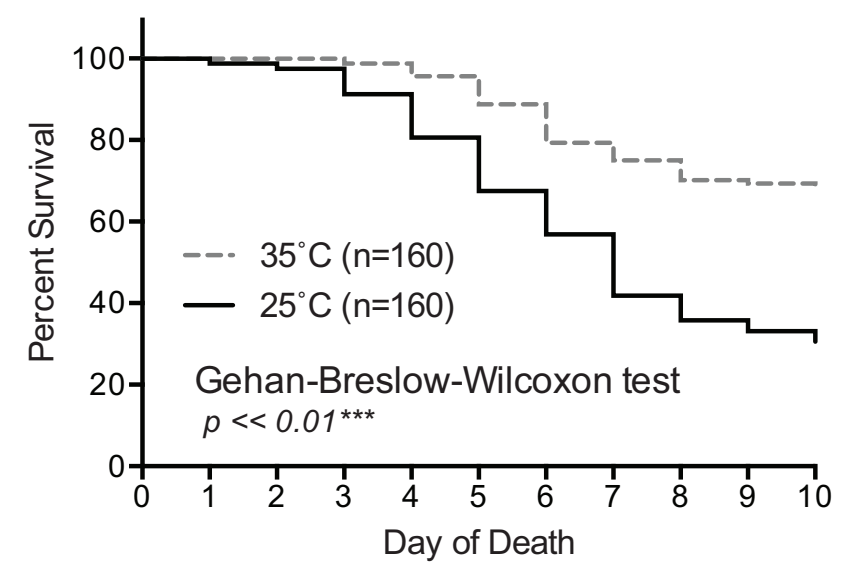

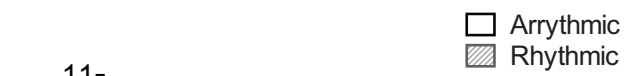

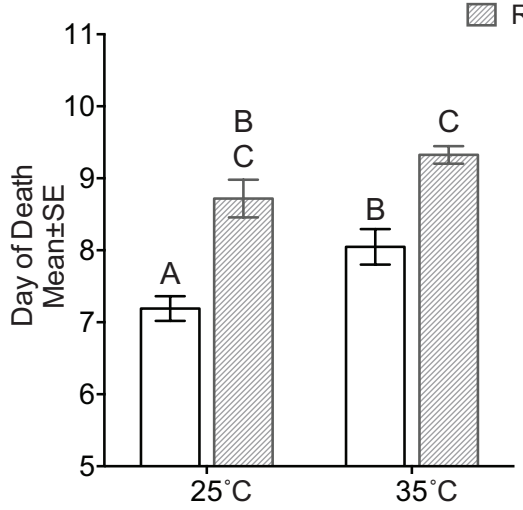

Figure 5. Mortality of isolated young workers greatly increases at $25^{\circ} \mathrm{C}$ and in arrhythmic individuals. A) Survival plot of 1-day-old honey bee cohorts at $25^{\circ} \mathrm{C}$ (solid line) and at $35^{\circ} \mathrm{C}$ (intermittent line). Both visual and statistical comparison of the cohorts revealed that survival of individuals was higher in the $35^{\circ} \mathrm{C}$ cohort (Gehan-Breslow-Wilcoxon, $n=320, p<<0.01$ ). B) Bar graph of mean survival and standard error of arrhythmic and rhythmic individuals separated by experimental cohort $\left(25^{\circ} \mathrm{C}\right.$ or $35^{\circ} \mathrm{C}$ ). Proportional Hazards model revealed that temperature and rhythmicity have independent effects on mortality in young workers (Temperature: $X^{2}=12.35, d f=1, p<<0.001$; Rhythm: $X^{2}=15.64$, df $=1$, $\mathrm{p}<<0.001$; Temperature*Rhythm: $\left.X^{2}=0.055 \mathrm{df}=1, \quad \mathrm{p}=0.8142\right)$ Wilcoxon each Pair test revealed significant differences $(p<0.05)$ between paired comparisons represented by different letters.

In this analysis environmental temperature, rhythmicity (whether the individual developed rhythms or was arrhythmic throughout the experiment) and the interaction of these factors were tested as the variables causing the observed mortality. The resulting analysis revealed that environmental temperature and rhythmicity, independently, have a significant effect on the mortality of young workers in our assay, while their interaction was not significant (Temperature: $\quad X^{2}=12.35, \quad d f=1, \quad p<<0.001 ; \quad$ Rhythm: $\quad X^{2}=15.64, \quad d f=1, \quad p<<0.001$; Temperature* Rhythm: $X^{2}=0.055 \mathrm{df}=1, \mathrm{p}=0.8142$ ). The combined results suggest that in our experiments mortality is caused by the environmental temperature and the inability to develop 
Our result that temperature positively influences the rate and proportion of individuals

266 developing circadian rhythms combined with the findings from a recent study (Eban-

267 Rothschild et al., 2012) that the first 48 hours in the colony influenced development of strong

268 circadian rhythms led us to postulate the following prediction: If temperature is a key factor in

269 the development of circadian rhythmicity during the first 48 hours after emergence in young

270 workers, then placing 1-day old workers at $35^{\circ} \mathrm{C}$ for the first 48 hours after emergence and

271 afterwards changing environmental temperature to $25^{\circ} \mathrm{C}$, will result in a greater proportion of

272 individuals developing circadian rhythms than 1 day-old workers placed at $25^{\circ} \mathrm{C}$. To test this

273 hypothesis, we placed 1-day old bees at either $35^{\circ} \mathrm{C}$ or $25^{\circ} \mathrm{C}$ group, after 48 hours, we

274 changed the temperature to $25^{\circ} \mathrm{C}$ in the first group $\left(35-25^{\circ} \mathrm{C}\right)$. Consistent with this prediction

275 we found that exposure to $35^{\circ} \mathrm{C}$ during the first 48 hours after emergence plays a significant

276 role in the development of circadian rhythms in young workers (Figure 6A). Repeated

277 measures comparison of the cumulative distribution of rhythmic individuals for the $35-25^{\circ} \mathrm{C}$

278 group and bees continuously at the $25^{\circ} \mathrm{C}$ group, was significantly different $(F=3.28, d f=6$,

$279 \mathrm{p}<0.01)$. In addition to the effects of temperature on the development of circadian rhythm, we

280 also observed significant differences in the survival of individuals exposed to $35^{\circ} \mathrm{C}$ for the first

28148 hours and those that were kept at $25^{\circ} \mathrm{C}$. By day 7 less than 12 individuals had died in the

$28235-25^{\circ} \mathrm{C}$ group, while more than 50 had died in the $25^{\circ} \mathrm{C}$ (Gehan-Breslow-Wilcoxon, $\mathrm{n}=256$,

$283 \mathrm{p}<<0.01)$. Taken together, temperature in the colony plays a key role in the development of

284 circadian rhythms of workers. 


\section{A) Cumulative dristribiution of Rhythmic bees}

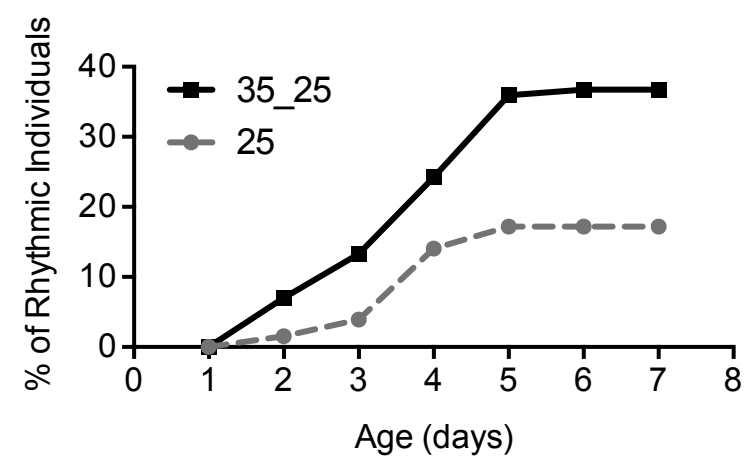

\section{B) Survival Analysis of bees at $35^{\circ} \mathrm{C}$ for the first $48 \mathrm{hrs}$ after emergance vs bees at $25^{\circ} \mathrm{C}$}

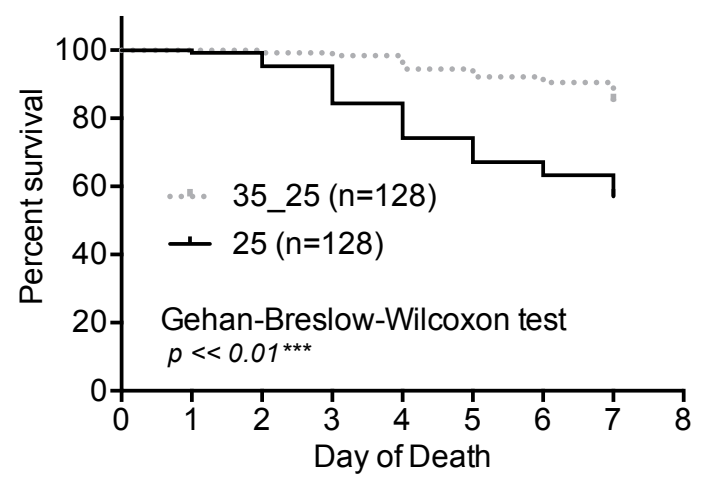

Figure 6. Temperature $\left(35^{\circ} \mathrm{C}\right)$ during the first 48 hours after emergence is sufficient to rescue the rhythmicity and mortality effects of $25^{\circ} \mathrm{C}$. A) Cumulative distribution of rhythmic young workers exposed to $35^{\circ} \mathrm{C}$ during the first 48 hours after emergence and afterwards placed at $25^{\circ} \mathrm{C}$ for the remainder of the experiment $\left(35-25^{\circ} \mathrm{C}\right)$ compared to that of bees placed at $25^{\circ} \mathrm{C}$ after emergence. Repeated measures MANOVA revealed significant differences between the rate and proportion of individuals developing rhythmic behavior under these conditions $(F=3.28, d f=6, p<0.01)$. B) Survival plot of 1-day-old honey bee cohorts at $25^{\circ} \mathrm{C}$ (solid line) and bees exposed to $35^{\circ} \mathrm{C}$ for the first 48 hours after emergence (intermittent line). Individuals in the $35-25^{\circ} \mathrm{C}$ cohort presented significantly better survival rates than bees placed at $25^{\circ} \mathrm{C}$ since the beginning of the experiment (Gehan-BreslowWilcoxon, $n=256, p<<0.01$ ).

\section{Discussion:}

In the current study, we show that colony temperature plays a key role in the ontogeny of circadian rhythms of young honey bee workers. Previous studies exploring the ontogeny of circadian rhythms of young workers established that circadian rhythms both in the field and in isolation commence around 7-9 days after eclosion (Bloch et al., 2001; Moore et al., 1998; Toma et al., 2000). Experiments that followed uncovered that exposure to the colony environment during the first 48 hours after eclosion significantly impacts the development of circadian rhythms under isolation (Eban-Rothschild et al., 2012). Here we show evidence indicating that the regulation of temperature $\left(\sim 35^{\circ} \mathrm{C}\right)$ in the colony is a key social factor 
311 determining the development of circadian rhythms. Placing 1-day old workers at the hive's

312 core temperature in the laboratory results in an accelerated rate and increased proportion of

313 individuals developing rhythmicity (Figure 1). Moreover, we show that this temperature is

314 particularly important during the first 48 hours after eclosion and kept exposure to $35^{\circ} \mathrm{C}$ in this

315 period is sufficient for early rhythm development (Figure 6). Analysis of the endogenous period

316 length variation of rhythmic bees, suggests that temperature may play a role in the

317 development of the neural circuitry that regulate circadian rhythms (Figures 2,3,4). Lastly,

318 mortality differences between experimental groups were associated with development of

319 circadian rhythms. Taken together, socially regulated temperature plays a key role in the

320 ontogeny of circadian rhythms in honey bee workers.

321 The proportion and rate of honey bee workers developing circadian rhythms in the

$32235^{\circ} \mathrm{C}$ cohort is consistent with work examining the effect of colony environment on circadian

323 rhythms, where after 48 hours of colony exposure between $60-80 \%$ of bees presented

324 circadian rhythms (Eban-Rothschild et al., 2012). In addition, individuals exposed to $35^{\circ} \mathrm{C}$ for

325 the first 48 hours after eclosion presented twice the proportion (40\%) of rhythmic bees than

326 bees that at $25^{\circ} \mathrm{C}(20 \%)$. This suggests that temperature is one of several factors that play a

327 role in the development of circadian rhythmicity. Furthermore, our results in the $25^{\circ} \mathrm{C}$ groups

328 are very similar to those of bees that only spent the the first 24 hours after eclosion inside the

329 colony (Eban-Rothschild et al., 2012). Further studies are needed to ascertain the relative

330 importance of temperature on the ontogeny of circadian rhythmicity compared to other colony

331 factors. Studying the neural changes that may occur during the critical period of 24-48 hours

332 after emergence in the honey bee nervous system, may provide clues as to the other factors

333 that influence development of circadian rhythms.

334 In our data and that of previous studies examining the ontogeny of circadian rhythms

335 in workers, we can observe that not all individuals develop circadian rhythms by the end of 
336 the experiment (Eban-Rothschild et al., 2012; Meshi and Bloch, 2007; Toma et al., 2000).

337 While the percent of arrhythmic individuals at $35^{\circ} \mathrm{C}$ is similar to that of previous studies at the

338 end of the experiment, at $25^{\circ} \mathrm{C}$ the percent of arrhythmic individuals more than double of that

339 in previous studies (Figure 1). One possible factor that is influencing this result is the time of

340 the year the experiments were carried out, which was winter in Puerto Rico. During winter

341 there are drastic changes in the colony demography and dynamics, such as reduction of brood

342 and complete cease of foraging behavior (Doke et al., 2015). These changes have been

343 mostly studied in temperate zones, where the seasons are marked by drastic changes in

344 weather and may not be necessarily applicable to Puerto Rico. Based on our current data set,

345 further experiments are required to accept or discard the effect of season in the ontogeny of

346 circadian rhythmicity.

$347 \quad$ Our results and those of other studies provide strong evidence that temperature plays

348 a key role in the ontogeny of circadian rhythms in young workers. However, other studies in

349 the field and laboratory provide evidence that other factors influence the development of

350 circadian rhythmicity, such as genetic background and social environment. Monitoring the

351 behavior of individual bees in the colony as they aged, researchers have shown that

352 rhythmicity, measured using standing behavior as the measure of inactivity in the colony,

353 found that bees of fast genotypes, which show accelerated behavioral development into

354 foragers (Giray and Robinson, 1994), present circadian rhythms as early as 4-7 days of age

355 in some cases, while the slow genotype bees did not show rhythms until the 16-19-day interval

356 (Moore et al., 1998). This finding is consistent with the onset of foraging in slow and fast

357 genotype groups (Giray et al., 1999). The authors of this study conclude that bees inside the

358 hive present rhythmic activity much earlier than onset of foraging. While in the current study

359 we did not control the genetic background of our bees, we did examine two different colonies

360 and obtained similar results. 
Since our experiments were performed in the laboratory and individuals were isolated,

362 we cannot measure in the current data set the effects of pheromone on the development of

363 circadian rhythms. However, studies have shown that exposure to the foragers advances

364 development of circadian rhythmicity, while bees housed with young bees of their same age

365 cohort develop rhythmicity later (Meshi and Bloch, 2007). Furthermore, young workers that

366 had direct contact with the brood did not show circadian rhythms even when outside the hive

367 and under light/dark cycles (Shemesh et al., 2007, 2010). Taken together, ontogeny of

368 circadian rhythms in the honey bee colony context is regulated by the socially regulated

369 factors of temperature, social interactions with brood, foragers and young workers, and

370 potentially genetic background.

371 Endogenous period length of young bees at $35^{\circ} \mathrm{C}(24.5 \pm 0.12 \mathrm{hr} \mathrm{SE})$ was on average

372 closer to the Earth's rotational period than that of individuals at $25^{\circ} \mathrm{C}(23.1 \pm 0.43 \mathrm{hr}$ SE) (Figure

3732 and Figure 3). This result is consistent with our previous work on honey bees and work on

374 Apis cerana where environmental temperature influenced endogenous period length,

375 suggesting that the circadian clock of young workers is able to compensate for environmental

376 temperature changes (Fuchikawa and I Shimizu, 2007; Giannoni-Guzmán et al., 2014). While

377 differences between $25^{\circ} \mathrm{C}$ and $35^{\circ} \mathrm{C}$ cohorts in average period length was consistent with that

378 of foragers, the degree of period length variation was different between young workers at $25^{\circ} \mathrm{C}$

379 and $35^{\circ} \mathrm{C}$, while the degree of variation in foragers at both $25^{\circ} \mathrm{C}$ and $35^{\circ} \mathrm{C}$ was similar to that

380 of young workers at $35^{\circ} \mathrm{C}$ (Figure 4). Since foraging is the last job a worker performs before

381 dying, these similarities in period length variation between young workers kept at $35^{\circ} \mathrm{C}$ and

382 foragers at both temperatures is most likely related to foragers having spent the majority of

383 their life inside the colony. The foragers in this study were captured at the entrance of the

384 colony, so we can assume that they had fully developed circadian rhythms. This result

385 suggests that bees exposed to $25^{\circ} \mathrm{C}$ from a young age may have differences in the 
386 development of the circadian network or present a lack of communication between different

387 clocks in the honey bee circadian system.

With regard to the survival rates observed in bees at $35^{\circ} \mathrm{C}$ and those at $25^{\circ} \mathrm{C}$ (Figure

389 5), our analysis indicates that environmental temperature and lack of rhythmicity are

390 independently decreasing survival rates. The effect of temperature on mortality is consistent

391 with our data that temperature is important for the development of circadian rhythmicity and

392 that changes in temperature during development can have long lasting effects later in the

393 honey bee's life (Becher et al., 2009; Jones et al., 2004; Tautz et al., 2003). It is possible that

394 in addition to development of circadian rhythms, other systems are still under development

395 and do not develop properly at $25^{\circ} \mathrm{C}$ causing the observed mortality.

396 Comparing the development of circadian rhythms of honey bee workers with that of

397 other insects suggests that the postembryonic ontogeny in honey bees may be a product of

398 the colony's social context. Studies examining the circadian rhythms of various insects show

399 rhythmic activity at even pre-adult stages (Fantinou et al., 1998; Kaneko and Hall, 2000; Page

400 and Block, 1980; Tomioka and Chiba, 1982). In the case of crickets and cockroaches,

401 circadian rhythmicity has been documented in pre-adult nymph stages and its patterns change

402 as individuals age (Page and Block, 1980; Tomioka and Chiba, 1982). In other insects such

403 as egg-parasitic wasp Telenomus busseolae, adult emergence is timed by their entrainment

404 of light/dark cycles, providing evidence of early development of the circadian system (Fantinou

405 et al., 1998). In contrast to honey bee brood which is kept at almost constant conditions, in

406 these insects the pre-adults (eggs, larvae, pupae, nymphs) are at the mercy of the external

407 environment and having a working circadian system becomes necessary for their survival. In

408 the case of honey bees, since conditions are constant during development, the ability to

409 predict changes in the environment during larval and pupal development becomes less

410 necessary, thus it is possible that honey bee circadian rhythms have evolved to developed 
411 after adult emergence when they are needed. For example, in marsupials, such as kangaroos,

412 where gestation is short and many developmental processes occur after birth, the front limbs

413 are much more developed than other systems because upon birth they are required in order

414 to climb to the maternal pouch and to the mother's nipple to feed (Wittmann, 1981, 1984). At

415 what exact stage of development and what processes are driving the ontogeny of circadian

416 rhythms in honey bee workers is a subject of further research.

417 In order to present circadian rhythms of locomotion, the connectivity between various

418 systems is necessary. At the brain level, it is known that multiple oscillators that control the

419 timing of locomotor activity, at different times of the day (e.g. morning and evening cells), not

420 only need to communicate but they need to synchronized in a specific manner (Stoleru et al.,

$4212004,2005)$. One of the possible processes that may be occurring in the first 48 hours after

422 emergence in workers is the establishment of connections between the multiple oscillators in

423 the honey bee brain. Another circuit that is necessary for locomotor rhythms is the connectivity

424 between motor neurons and the different oscillators in the brain (Blanchardon et al., 2001).

425 Motor neurons are organized forming central pattern generators that coordinate the

426 movement of extremities independently of the brain. However, without a signal from the brain,

427 the initiation and regulation of locomotor rhythms is not possible (Allada et al., 1998). If the

428 formation of this connection is regulated by temperature in honey bees and is occurring in this

429 48-hour window after emergence, then arrhythmicity may be explained by the failure to 430 establish this connection.

An additional process that is important in the regulation of circadian locomotion is the

432 connections between motor neurons and muscles (i.e. Neuromuscular junction (NMJ). This

433 connectivity has been studied extensively in multiple insects, and the cellular and molecular

434 processes have been well characterized in Drosophila (H Keshishian et al., 2003).

435 Experiments exploring the effects of temperature on this connections show a temperature 
436 dependent plasticity of motor nerve terminal arborization, where at higher temperatures more

437 arborization of the nerve terminal occurs (Zhong, 2004). In honey bees, measuring circadian

438 gene expression in the brain and muscle of young arrhythmic workers indicates that the

439 muscle clock oscillates, while the brain's clock did not seem to oscillate (Ben Attia, 2014).

440 Based on what is known in other models and this finding it is possible that different oscillators

441 in the brain have not synchronized with each other and that the connection between the brain's

442 oscillators and peripheral oscillators, at the time of collection, has not been established and

443 requires further research.

444 In conclusion, this study shows for the first time the effects of colony temperature on

445 the ontogeny of circadian rhythms, specifically during the first two days after adult emergence.

446 Future studies will examine the weight of temperature as a factor in the development of

447 circadian rhythms and examine the weight of other factors, such as genetic background and

448 social cues. In addition, carefully examining the changes at the neural and gene expression

449 levels occurring during the first 48 hours may provide insight into the mechanisms driving the

450 ontogeny of circadian rhythms in honey bee workers, which remain to be elucidated.

\section{Acknowledgements:}

452 We would like to thank Dr. Arian Avalos and Emmanuel Rivera, for help with the

453 experiments. Thanks Dr. Luis de Jesus for their comments and suggestions. We would also

454 like to recognize the director, Manuel Diaz and the personnel of the Gurabo Experimental

455 Agriculture Station of the University of Puerto Rico at Mayaguez for use of facilities at "Casa

456 Amarilla". This work was sponsored by the National Science Foundation (NSF) awards

$4571026560,1633184,1707355$ and the National Institute of Health (NIH) 2R25GM061151-13, 458 P20GM103475. 


\section{References:}

461 Allada R; NE White; W V So; JC Hall and M Rosbash (1998) A mutant Drosophila homolog 462 of mammalian Clock disrupts circadian rhythms and transcription of period and 463 timeless. Cell 93(5): 791-804. Available from:

$464 \quad$ http://www.ncbi.nlm.nih.gov/pubmed/9630223.

465 Becher MA; H Scharpenberg and RF Moritz (2009) Pupal developmental temperature and 466 behavioral specialization of honeybee workers (Apis mellifera L.). Journal of 467 comparative physiology. A, Neuroethology, sensory, neural, and behavioral physiology 468 195(7): 673-679. Available from: http://www.ncbi.nlm.nih.gov/pubmed/19390855.

469 Ben-Shahar Y (2003) cGMP-dependent changes in phototaxis: a possible role for the foraging gene in honey bee division of labor. Journal of Experimental Biology 206(14):

473 Blanchardon E; B Grima; A Klarsfeld; E Chelot; PE Hardin; T Preat and F Rouyer (2001) 474 Defining the role of Drosophila lateral neurons in the control of circadian rhythms in 2507-2515. Available from: http://jeb.biologists.org/cgi/doi/10.1242/jeb.00442 (accessed 1 November 2014).

478 Bloch G; DP Toma and GE Robinson (2001) Behavioral Rhythmicity, Age, Division of Labor 479 and period Expression in the Honey Bee Brain. Journal of biological rhythms 16(5): $480 \quad 444-456$.

481 Bloch G; JP Sullivan and GE Robinson (2002) Juvenile hormone and circadian locomotor 482 activity in the honey bee Apis mellifera. Journal of insect physiology 48: 1123-1131. 
management. Current Opinion in Insect Science 10: 185-193. Available from: http://www.sciencedirect.com/science/article/pii/S2214574515000930 (accessed 16 June 2015).

Eban-Rothschild A; Y Shemesh and G Bloch (2012) The colony environment, but not direct contact with conspecifics, influences the development of circadian rhythms in honey

491 Fantinou AA; MP Alexandri and JA Tsitsipis (1998) Adult emergence rhythm of the eggbees. 2012/06/02 ed. Journal of biological rhythms 27(3): 217-225. Available from:

493 Fuchikawa T and I Shimizu (2007) Circadian rhythm of locomotor activity in the Japanese honeybee, Apis cerana japonica. Physiological Entomology 32(1): 73-80.

495 Fuchikawa T and I Shimizu (2007) Effects of temperature on circadian rhythm in the Japanese honeybee, Apis cerana japonica. Journal of insect physiology 53(11): 1179_

499 Giannoni-Guzmán MA; A Avalos; J Marrero Perez; EJ Otero Loperena; M Kayım; JA

500 Medina; SE Massey; M Kence; A Kence; T Giray and JL Agosto-Rivera (2014)

$501 \quad$ Measuring individual locomotor rhythms in honey bees, paper wasps and other similar502 sized insects. The Journal of experimental biology 217(Pt 8): 1307-15. Available from: 503 http://www.ncbi.nlm.nih.gov/pubmed/24436380 (accessed 30 July 2014).

504 Giray T and GE Robinson (1994) Effects of intracolony variability in behavioral development 505 on plasticity of division of labor in honey bee colonies. Behavioral Ecology and 506 Sociobiology 35(1): 13-20. Available from:

507 http://link.springer.com/10.1007/BF00167054 (accessed 25 September 2014). 
508 Giray T; E Guzman-Novoa; CW Aron; B Zelinsky; SE Fahrbach and GE Robinson (1999)

509 Genetic variation in worker temporal polyethism and colony defensiveness in the honey

510 bee, Apis mellifera. Behavioral Ecology 11(1): 44-55. Available from: <Go to

$511 \quad$ ISI>://WOS:000088355900007.

512 Goodwin RM and D Lewis (1987) Honeybees use a biological clock to incorporate sun

513 positions in their waggle dances after foraging under heavy overcast skies. New Zeland

$514 \quad$ Entomologist 10: 138-140.

515 H Keshishian; K Broadie; and A Chiba and M Bate (2003) The Drosophila Neuromuscular

$516 \quad$ Junction: A Model System for Studying Synaptic Development and Function. Annual

517 Reviews 4139 El Camino Way, P.O. Box 10139, Palo Alto, CA 94303-0139, USA.

$518 \quad$ Available from:

519 http://www.annualreviews.org/doi/abs/10.1146/annurev.ne.19.030196.002553?journalC

520 ode=neuro (accessed 23 May 2016).

521 Human H; SW Nicolson and V Dietemann (2006) Do honeybees, Apis mellifera scutellata,

522 regulate humidity in their nest? Die Naturwissenschaften 93(8): 397-401. Available

523 from: http://www.ncbi.nlm.nih.gov/pubmed/16670906 (accessed 29 February 2016).

524 Jones JC; MR Myerscough; S Graham and BP Oldroyd (2004) Honey bee nest

525 thermoregulation: diversity promotes stability. Science 305(5682): 402-404. Available

526 from: http://www.ncbi.nlm.nih.gov/pubmed/15218093.

527 Jones JC; P Nanork and BP Oldroyd (2007) The role of genetic diversity in nest cooling in a

528 wild honey bee, Apis florea. Journal of comparative physiology. A, Neuroethology,

529 sensory, neural, and behavioral physiology 193(2): 159-65. Available from:

530 http://www.ncbi.nlm.nih.gov/pubmed/17013621 (accessed 27 January 2014).

531 Kaneko M and JC Hall (2000) Neuroanatomy of cells expressing clock genes in Drosophila: 
Transgenic manipulation of the period and timeless genes to mark the perikarya of circadian pacemaker neurons and their projections. Journal of Comparative Neurology 534 422(1): 66-94.

535 Kronenberg F and HC Heller (1982) Colonial thermoregulation in honey bees (Apis

536 mellifera). Journal of Comparative Physiology ? B 148(1): 65-76. Available from:

537 http://link.springer.com/10.1007/BF00688889 (accessed 18 April 2014).

538 Levine JD; P Funes; HB Dowse and JC Hall (2002) Signal analysis of behavioral and

539 molecular cycles. BMC neuroscience 3: 1. Available from:

540 http://www.pubmedcentral.nih.gov/articlerender.fcgi?artid=65508\&tool=pmcentrez\&ren

541 dertype=abstract.

542 Meshi A and G Bloch (2007) Monitoring circadian rhythms of individual honey bees in a

543 social environment reveals social influences on postembryonic ontogeny of activity

544 rhythms. Journal of biological rhythms 22(4): 343-355. Available from:

545 http://www.ncbi.nlm.nih.gov/pubmed/17660451.

546 Moore D (2001) Honey bee circadian clocks: behavioral control from individual workers to

$547 \quad$ whole-colony rhythms. Journal of insect physiology 47: 843-857.

548 Moore D and MA Rankin (1985) Circadian locomotor rhythms in individual honey bees.

549 Physiological Entomology 10: 191-197.

550 Moore D; JE Angel; IM Cheeseman; SE Fahrbach and GE Robinson (1998) Timekeeping in 551 the honey bee colony: integration of circadian rhythms and division of labor. Behav $552 \quad$ Ecol Sociobiol 43: 147-160.

553 Ohashi M; H Ikeno; T Kimura; T Akamatsu; R Okada and E Ito (2008) Control of hive 554 environment by honeybee (Apis mellifera) in Japan. Proceeding(1961): 2008.

555 Page TL and GD Block (1980) Circadian rhythmicity in cockroaches: Effects of early post- 
embryonic development and aging. Physiological Entomology 5(3): 271-281.

557 SAS Institute Inc. (2009) JMP® 8 User Guide. Second Edi. Cary, NC: SAS.

558 Seeley TD (1974) Atmospheric carbon dioxide regulation in honey-bee (Apis mellifera)

559 colonies. Journal of Insect Physiology 20(11): 2301-2305. Available from:

560 http://www.sciencedirect.com/science/article/pii/0022191074900523 (accessed 17

$561 \quad$ March 2016).

562 Shemesh Y; M Cohen and G Bloch (2007) Natural plasticity in circadian rhythms is mediated 563 by reorganization in the molecular clockwork in honeybees. 2007/03/16 ed. FASEB

564 21(10): 2304-2311. Available from: http://www.ncbi.nlm.nih.gov/pubmed/17360847.

565 Shemesh Y; A Eban-Rothschild; M Cohen and G Bloch (2010) Molecular dynamics and

566 social regulation of context-dependent plasticity in the circadian clockwork of the honey

567 bee. 2010/09/17 ed. The Journal of neuroscience : the official journal of the Society for

$568 \quad$ Neuroscience 30(37): 12517-12525. Available from:

569 http://www.ncbi.nlm.nih.gov/pubmed/20844146 (accessed 1 April 2014).

570 Simpson J (1961) Nest Climate Regulation in Honey Bee Colonie: Honey bees control their

571 domestic environment by methods based on their habit of clustering together. Science

572 (New York, N.Y.) 133(3461): 1327-33. Available from:

573 http://www.ncbi.nlm.nih.gov/pubmed/17744947 (accessed 17 March 2016).

574 Spangler HG (1972) Daily Activity Rhythms of Individual Worker and Drone Honey Bees.

$575 \quad$ Annals of the Entomological Society of America 65(5): 1073-1076.

576 Stoleru D; Y Peng; JL Agosto-Rivera and M Rosbash (2004) Coupled oscillators control

577 morning and evening locomotor behaviour of Drosophila. 2004/10/16 ed. Nature

578 431(7010): 862-868. Available from: http://www.ncbi.nlm.nih.gov/pubmed/15483615.

579 Stoleru D; Y Peng; P Nawathean and M Rosbash (2005) A resetting signal between 
Drosophila pacemakers synchronizes morning and evening activity. 2005/11/11 ed. Nature 438(7065): 238-242. Available from: http://www.ncbi.nlm.nih.gov/pubmed/16281038.

583 Tautz J; S Maier; C Groh; W Rossler and A Brockmann (2003) Behavioral performance in

584 adult honey bees is influenced by the temperature experienced during their pupal 585 development. Proceedings of the National Academy of Sciences of the United States of 586 America 100(12): 7343-7347. Available from:

$587 \quad$ http://www.ncbi.nlm.nih.gov/pubmed/12764227.

588 Toma DP; G Bloch; D Moore and GE Robinson (2000) Changes in period mRNA levels in 589 the brain and division of labor in honey bee colonies. Proceedings of the National $590 \quad$ Academy of Sciences of the United States of America 97(12): 6914-6919.

591 Tomioka K and Y Chiba (1982) Post-embryonic development of circadian rhythm in the $592 \quad$ cricket, Gryllus bimaculatus: A rhythm reversal. Journal of Comparative Physiology ??? $593 \quad$ A 147(3): 299-304.

594 Van Nest BN and D Moore (2012) Energetically optimal foraging strategy is emergent 595 property of time-keeping behavior in honey bees. Behavioral Ecology 23(3): 649-658.

596 Available from: http://www.beheco.oxfordjournals.org/cgi/doi/10.1093/beheco/ars010 $597 \quad$ (accessed 26 May 2014).

598 von Frisch K (1967) The Dance Language and Orientation of Bees. Cambridge, MA.: $599 \quad$ Harvard University Press.

600 Wagner AE; BN Van Nest; CN Hobbs and D Moore (2013) Persistence, reticence and the 601 management of multiple time memories by forager honey bees. The Journal of 602 experimental biology 216(Pt 7): 1131-1141. Available from:

603 http://www.ncbi.nlm.nih.gov/pubmed/23197093. 
604 Winston ML (1987) The biology of the honey bee. Cambridge, MA: Harvard University

$605 \quad$ Press.

606 Wittmann KJ (1981) Comparative biology and morphology of marsupial development in

607 Leptomysis and other Mediterranean Mysidacea (Crustacea). Journal of experimental

608 marine Biology and Ecology, Elsevier 52(2): 243-270.

609 Wittmann KJ (1984) Ecophysiology of marsupial development and reproduction in

610 Mysidacea (Crustacea). Oceanogr Mar Biol Annu Rev 22: 393-428.

611 Zhong Y (2004) Neuronal Activity and Adenylyl Cyclase in Environment-Dependent

612 Plasticity of Axonal Outgrowth in Drosophila. Journal of Neuroscience 24(6): 1439-

613 1445. Available from: http://www.jneurosci.org/cgi/doi/10.1523/JNEUROSCI.0740-

$614 \quad 02.2004$

615

616 